Brief Communication

\title{
Validation of MATLAB algorithm to implement a two-step parallel pyrolysis model for the prediction of maximum \%char yield
}

\author{
Ibiba Taiwo Horsfall ${ }^{1,2}$. Macmanus Chinenye Ndukwu' ${ }^{1}$. Fidelis Ibiang Abam ${ }^{3}$. Ololade Moses Olatunji ${ }^{4}$. \\ Ojong Elias Ojong ${ }^{5} \cdot$ Keavey Osa-Aria ${ }^{6}$
}

Received: 11 February 2021 / Accepted: 10 June 2021

Published online: 01 July 2021

(c) The Author(s) 2021 OPEN

\begin{abstract}
Numerical modeling of biomass pyrolysis is becoming a cost and time-saving alternative for experimental investigations, also to predict the yield of the by-products of the entire process. In the present study, a two-step parallel kinetic model was used to predict char yield under isothermal condition. MATLAB ODE45 function codes were employed to solve a set of differential equations that predicts the \%char at varying residence times and temperatures. The code shows how the various kinetic parameters and mass of pyrolysis products were determined. Nevertheless, the algorithm used for the prediction was validated with experimental data and results from past works. At $673.15 \mathrm{~K}$, the numerical simulation using ODE45 function gives a char yield of $27.84 \%$. From $573.15 \mathrm{~K}$ to $673.15 \mathrm{~K}$, char yield ranges from 31.7 to $33.72 \%$ to $27.84 \%$ while experimental yield decreases from 44 to $22 \%$. Hence, the error between algorithm prediction and experimental data from literature is -0.26 and 0.22 . Again, comparing the result of the present work with the analytical method from the literature showed a good agreement.
\end{abstract}

Keywords MATLAB codes · Pyrolysis kinetic model $\cdot$ Mass of biochar

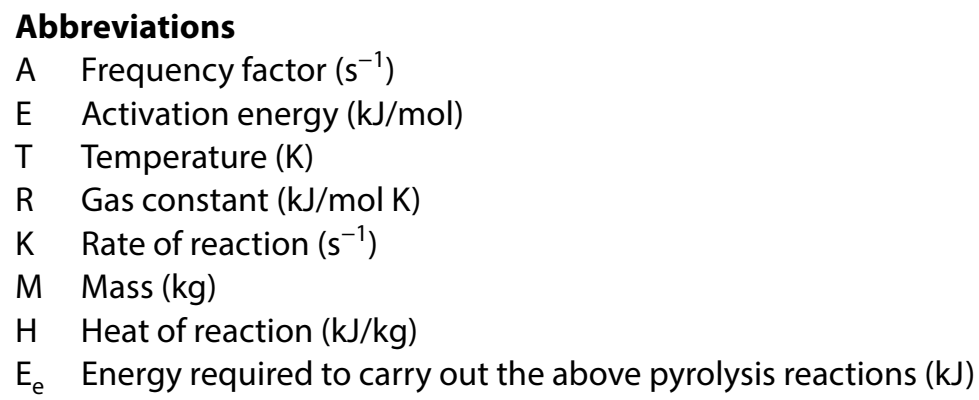

\footnotetext{
$\triangle$ Ibiba Taiwo Horsfall, ibibath@gmail.com; Macmanus Chinenye Ndukwu, ndukwumcu@gmail.com; Fidelis Ibiang Abam, abamo124@ gmail.com; Ololade Moses Olatunji, ololade_moses1@yahoo.com; Ojong Elias Ojong, eliasojong@gmail.com; Keavey Osa-Aria, osaariaprince@gmail.com | ${ }^{1}$ Department of Agricultural and Bioresources Engineering, Michael Okpara University of Agriculture, Umudike, P.M.B 7267, Umuahia, Abia State, Nigeria. ${ }^{2}$ Department of Environmental Engineering, IBIBATH MULTI SERVICES, Port Harcourt, Nigeria. ${ }^{3}$ Energy, Exergy and Environment Research (EERG) Group, Department of Mechanical Engineering, Michael Okpara University of Agriculture, Umudike, P.M.B. 7267, Umuahia, Abia State, Nigeria. ${ }^{4}$ Department of Agricultural Engineering, Akwa Ibom State University, Ikot Akpadem, Mkpat-Enin LGA, Akwa Ibom State, Nigeria. ${ }^{5}$ Department of Chemical Engineering, Faculty of Engineering and Technology, University of Calabar, P.M.B. 1115, Calabar, Cross River State, Nigeria. ${ }^{6}$ Department of Mechanical Engineering, Michael Okpara University of Agriculture, Umudike, P.M.B. 7267, Umuahia, Abia State, Nigeria.
} 


\section{Introduction}

Numerical simulations provide a more detailed insight in various aspects of pyrolysis processes under varying conditions. Pyrolysis being the first stage in any thermal treatment of biomass [1]. Studies have shown that its kinetics and products have a significant influence on the process [2]. However, char produced during pyrolysis of biomass not only reduces the amount of carbon emitted into the atmosphere, but it is also an eco-friendly alternative for activated carbon and other carbon materials [3]. Many models have no closed form solutions and hence it is a need to seek approximate solutions by means of numerical methods [4]. According to Atkinson et al. [5], it is possible to find closed form solutions for simple differential equations. An ordinary differential equation (ODE) is an equation that contains an independent variable, a dependent variable, and derivatives of the dependent variable. For some reasons, MATLAB does not include Euler functions. However, it has very sophisticated ones using Runge-Kutta algorithms. MATLAB has several different functions (built-ins) for the numerical solution of ordinary differential equations (ODE). The problems of solving an ODE are classified into initial-value problems (IVP) and boundary-value problems (BVP), depending on how the conditions at the endpoints of the domain are specified $[6,7]$. All the conditions of an initial-value problem are specified at the initial point. On the other hand, the problem becomes a boundary-value problem if the conditions are needed for both initial and final points $[8,9]$. An ordinary differential equation (ODE) is an equation that contains an independent variable, a dependent variable, and derivatives of the dependent variable. Many studies have not shown the solution to two-step parallel pyrolysis kinetics involving the prediction of pyrolysis products due to complex nature of the equations, and too many unknown variables. It has been established that the overall process of pyrolysis appears simple but the sequence of reactions is complex and involves both endothermic and exothermic processes whose thermodynamics and kinetics are poorly understood $[10,11]$. Under such complex phenomena, it is impossible to formulate a complete mathematical model of pyrolysis which will still be mathematically tractable. Yang et al. [12] presented that the major stage of biomass pyrolysis occurs between 250 and $450^{\circ} \mathrm{C}$. The two-step parallel reaction model of biomass pyrolysis has previously been used by other researchers [12-18] as reported by Sobamowo et al. [11]. Again, Babu and Chaurasia [19] studied numerically the effects of heating conditions, heating rates and order of the kinetic reactions on wood pyrolysis using the twostep model of Koufopanos et al. [20]. The model developed by Sobamowo et al. [11] it was based on Shafizadeh and Chin's model [13] which has been stated to be the most classical models for wood pyrolysis [21], the model was solved using the developed Runge-Kutta fifth-order for the simultaneous equations following the analytical method, only primary products where predicted. Most authors have focused on wood pyrolysis for primary reaction only, heating rate and effect on biomass particle, only very few reports on prediction of pyrolysis products for primary products especially [char, tar (bio-oil), and gas]. Sobamowo et al. [11] studied the pyrolysis of shrinking biomass particle in fixed bed gasifier and predicted the product yields (char, gas, and tar) using wood biomass. Presently no report on prediction of pyrolysis products under two-step parallel pyrolysis reaction scheme, which forms the novelty of this research.

This study has simplified the steps involved to implement a two-step parallel pyrolysis kinetics to predict the maximum char yield during primary and secondary reaction (char ${ }_{1}$, gas $_{1}, \operatorname{tar}_{\text {(bio-oil), } \text { char }_{2} \text { and gas }}$ ) using ODE45 MATLAB function. ODE45 is based on an explicit Runge-Kutta formula, the Dormand-Prince pair [22]. The numerical solver ODE45 combines a fourth order method and a fifth order method. This method varies the step size, choosing the step size at each step in an attempt to achieve the desired accuracy. In general, ODE45 is the best function to apply for most problems [23]. The purpose of study is to show the details of implementing the typical steps of numerical solution, so that it will be clear exactly what computations are being executed.

\section{Materials and methods}

In this study, a two-step parallel pyrolysis model was implemented through MATLAB ODE-45 algorithm to solve a set of differential equations (see Eqs. 2-7). The ODE 45 is function handle that evaluates the right side of the differential equations [24]. All solvers solve systems of equations in the form $y^{\prime}=f(t, y)$ or problems that involve a mass matrix, $M(t, y) y^{\prime}=f(t, y)$. The ode 45 solver can solve only equations with constant mass matrices [25]. The analytical model consisting of 6 partial differential equations was simulated in MATLAB 2019 with ODE 45 function which showed a plot of mass loss rate for the biomass and the various products. A set of differential equations for predicting parallel pyrolysis kinetics has been proposed by Di Blasi [26]. 


\subsection{Pyrolysis kinetics}

According to Di Blasi [26], the primary reaction is the thermal degradation of biomass into gas, tar, and char; eventually, when the temperature reaches a higher value, (see Fig. 1) tar decomposes into gas and char in secondary reactions. The first three reactions are endothermic, while the fourth and fifth are exothermic. The mechanism adopted for kinetic modeling in this study is presented in Fig. 1. The dependence on temperature is intrinsically introduced with the equilibrium constants $k_{i}$ of primary $\left(k_{1}, k_{2}, k_{3}\right)$ and secondary $\left(k_{4}, k_{5}\right)$ reactions. They may be expressed with the Arrhenius correlation [27]:

$$
\mathrm{k}_{\mathrm{i}}=\mathrm{A}_{\mathrm{i}} \mathrm{e}^{-\mathrm{E}_{\mathrm{i}} /(\mathrm{RT})} \quad \mathrm{i}=1,2, \ldots 5,
$$

$A$ is the frequency factor, $E$ is the activation energy, $R$ is the gas constant, and $T$ is the temperature at which the reaction takes place.

According to the two-stage parallel reaction model shown above in Fig. 1, the wood biomass undergoes thermal degradation according to primary reactions $\left(\mathrm{k}_{1} ; \mathrm{k}_{2} ; \mathrm{k}_{3}\right)$ giving gas $\mathrm{s}_{1}$, tar, and char ${ }_{1}$ as products at $\mathrm{T}=473.15 \mathrm{~K}$ where the biomass absorbs heat energy (endothermic reaction) from the surroundings to form products. However, tar may undergo secondary reactions $\left(k_{4}, k_{5}\right)$ at $\mathrm{T}>473.15 \mathrm{~K}$ where heat energy is released (exothermic reaction) to produce gas and char $_{2}$. The yields of the different products ranging from 1 to 5 , and the contemporary diminution of the biomass is a function of both time and temperature. Mass loss with time may be expressed as shown in Eqs. (2-7) according to Fantozzi et al. [27]:

$$
\begin{gathered}
\frac{\mathrm{dm}_{\mathrm{B}}}{\mathrm{dt}}=-\mathrm{m}_{\text {Biomass }}\left(\mathrm{k}_{1}+\mathrm{k}_{2}+\mathrm{k}_{3}\right) . \\
\frac{\mathrm{dm}_{\text {gas } 1}}{\mathrm{dt}}=\mathrm{m}_{\text {Biomass }} \mathrm{k}_{1} . \\
\frac{\mathrm{dm}_{\mathrm{tar}}}{\mathrm{dt}}=\mathrm{k}_{2} \mathrm{~m}_{\text {Biomass }}-\mathrm{m}_{\mathrm{tar}}\left(\mathrm{k}_{4}+\mathrm{k}_{5}\right) . \\
\frac{\mathrm{dm}_{\text {char1 }}}{\mathrm{dt}}=\mathrm{k}_{3} \mathrm{~m}_{\text {Biomass }} . \\
\frac{\mathrm{dm}_{\mathrm{gas} 2}}{\mathrm{dt}}=\mathrm{k}_{4} \mathrm{~m}_{\mathrm{tar}} . \\
\mathrm{dt}
\end{gathered}
$$

The energy required to carry out the above pyrolysis reactions can be expressed as the product of the mass-produced and the heat of reaction [27]:

$$
\mathrm{E}_{\mathrm{ei}}=\mathrm{H}_{\mathrm{i}} \mathrm{m}_{\mathrm{i}},
$$

Fig. 1 Modified two-step parallel reaction model of biomass pyrolysis

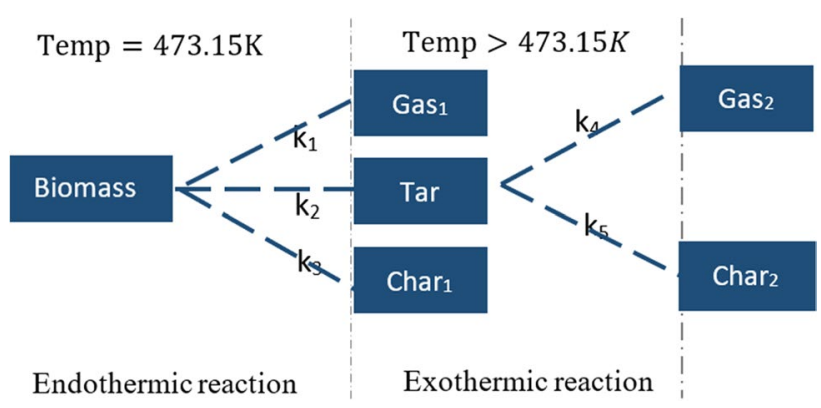


where, the index $i$ refers to the five reactions $E$ and $m$ were the energy required by, or released from, the ith reaction and the mass-produced, while $h$ is the heat of reaction (negative for $i=1$ to 3 and positive for $i=4$ to 5 ). Since this study adopts a two-step parallel kinetics mechanism, where tar also known as bio-oil decomposes into gas ${ }_{2}$ and char $_{2}$. The above equation can be can be expressed in terms biochar and gas obtained from primary and secondary reactions, respectively as:

$$
\mathrm{m}_{\text {biomass }}=\mathrm{m}_{\text {biochar } 1}+\mathrm{m}_{\text {gas } 1}+\mathrm{m}_{\text {gas } 2}+\mathrm{m}_{\text {biochar } 2} \text {. }
$$

Additionally, biochar yield was calculated using Eq. (9) below and expressed in mass percentage basis (\%) according to Nurhidayah et al. [28] as:

$$
\text { Biochar yield }(\%)=\frac{\text { mass of biochar }}{\text { mass of biomass }} \times 100 \text {. }
$$

Initial mass of biomass of $0.5 \mathrm{~kg}$ was considered for the numerical simulation. The kinetic parameters sourced from past works (see Table 1), it shows the constant parameters used for the simulations of the kinetics and heat transfer during the pyrolysis of wood. Since, thermogravimetric analysis (TGA) was carried out on pyrolysis of wood to predict the kinetic parameters. The simulation in the present study was considers pyrolysis of wood based on availability of kinetic data from TGA for a two-step parallel reaction.

In Table 1, A represents the frequency factor, $\mathrm{E}$ is the activation energy, $\mathrm{H}$ is the heat of reaction and $\mathrm{R}$ is gas constant. The rate of reaction constants was computed in MATLAB 2019 using Arrhenius equation (Eq. 1) using the activation energy, frequency factor and gas constant from Table 1 for the primary and secondary reactions, respectively. These constant values were selected based on slow pyrolysis since the target by-product is biochar. The computed rate of reaction constants, initial mass of the biomass and reaction time of 5400-9000 s were entered into the set of differential equations (Eqs. 2-7). The set of differential equations was solved by an algorithm developed in this study using the MATLAB ODE 45 function. The following procedure has been designed to implement the algorithm.

\subsection{Algorithms}

These lines are steps undertaken to generate the codes for the model implementation and kinetic parameters used in the study.

\subsubsection{Algorithm 1}

This section calculates the kinetic parameters for the primary and secondary reactions at varying temperatures with a user-defined function.

Table 1 Constant parameters used in simulation

\begin{tabular}{lll}
\hline Parameter & Value & References \\
\hline $\mathrm{A}_{1}\left(\mathrm{~s}^{-1}\right)$ & $1.30 \times 10^{8}$ & {$[41]$} \\
$\mathrm{A}_{2}\left(\mathrm{~s}^{-1}\right)$ & $2.00 \times 10^{8}$ & {$[41]$} \\
$\mathrm{A}_{3}\left(\mathrm{~s}^{-1}\right)$ & $1.08 \times 10^{7}$ & {$[41]$} \\
$\mathrm{A}_{4}\left(\mathrm{~s}^{-1}\right)$ & $4.28 \times 10^{6}$ & {$[42]$} \\
$\mathrm{A}_{5}\left(\mathrm{~s}^{-1}\right)$ & $1.00 \times 10^{5}$ & {$[42]$} \\
$\mathrm{E}_{1}(\mathrm{~kJ} / \mathrm{mol})$ & 140 & {$[41]$} \\
$\mathrm{E}_{2}(\mathrm{~kJ} / \mathrm{mol})$ & 133 & {$[41]$} \\
$\mathrm{E}_{3}(\mathrm{~kJ} / \mathrm{mol})$ & 121 & {$[41]$} \\
$\mathrm{E}_{4}(\mathrm{~kJ} / \mathrm{mol})$ & 107 & {$[42]$} \\
$\mathrm{E}_{5}(\mathrm{~kJ} / \mathrm{mol})$ & 107 & {$[42]$} \\
$\mathrm{R}(\mathrm{kJ} / \mathrm{mol} \mathrm{K})$ & $8.314 \times 10^{-3}$ & \\
$\mathrm{H}_{1}=\mathrm{H}_{2}=\mathrm{H}_{3}(\mathrm{~kJ} / \mathrm{kg})$ & 420 & {$[43]$} \\
$\mathrm{H}_{4}=\mathrm{H}_{5}(\mathrm{~kJ} / \mathrm{kg})$ & -40 & {$[44]$} \\
\hline
\end{tabular}




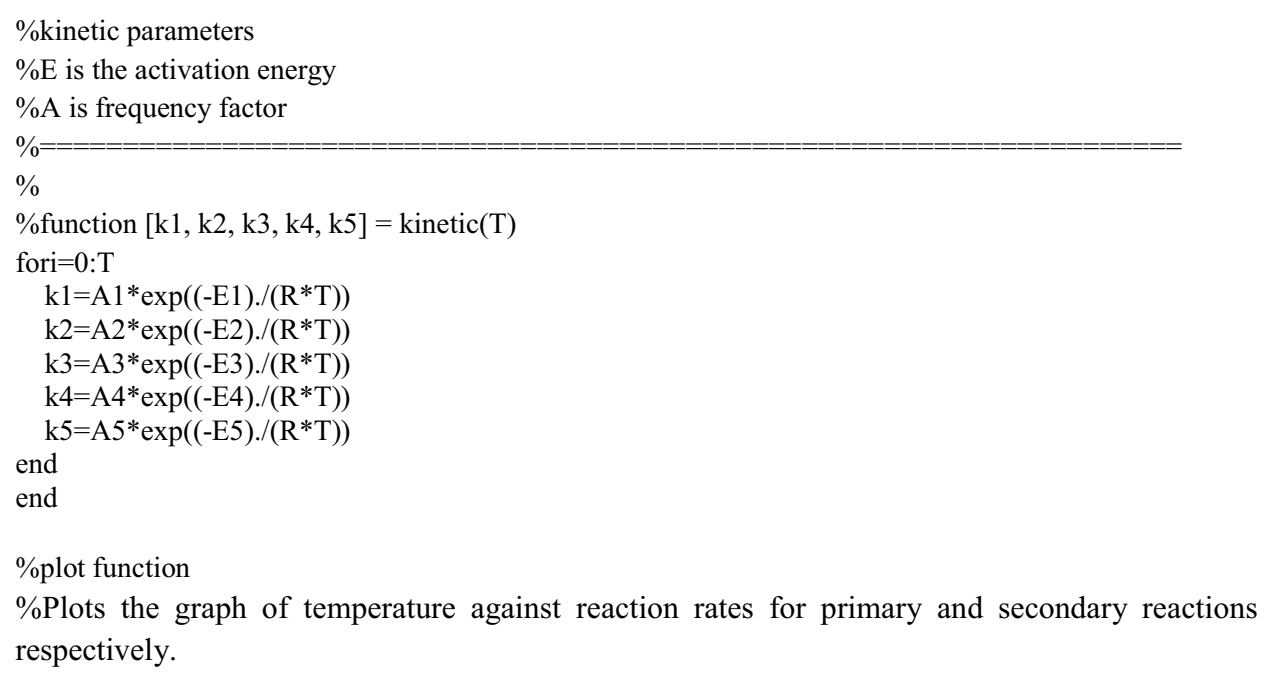

\subsubsection{Algorithm 2}

\%MATLAB simulation Codes for the implementation two-step parallel pyrolysis kinetic model.

$\%$ MATLAB simulation Codes for the implementation two-step parallel pyrolysis kinetic model

$\%============================================+1$
$\% \mathrm{t}=$ residence time $(\mathrm{s}) \% \mathrm{~m}=$ mass of biomass $(\mathrm{kg}) \% \mathrm{k}=$ rate of reaction

$\%$ Temperature $=573.15 \mathrm{~K}$

$\%=$

This function calculates the pyrolysis products yield by using the differential equations in Eq. 2 7 using the following rate constants. In the function t represents time, $\mathrm{m}$ represents the mass of product. The computation is done repeatedly for different temperatures using an iterative method.

\%function name and handle function $\mathrm{dm}=$ pyrolysis $1(\mathrm{t}, \mathrm{m})$

$\%$ Input the rate constants

$\%$ Pyrolysis model equations

$\%$ Equations 2-7

iteration 1: at $\mathrm{T}=623.15 \mathrm{~K}$

iteration 2 : at $\mathrm{T}=673.15 \mathrm{~K}$

iteration 3 : at $\mathrm{T}=723.15 \mathrm{~K}$

\%function $\mathrm{dm}=$ pyrolysis $4(\mathrm{t}, \mathrm{m})$

end

\subsubsection{Algorithm 3}

This part contains the simulation codes using ODE 45 function, it is divided into sub-sections to showing the temperature variations. 


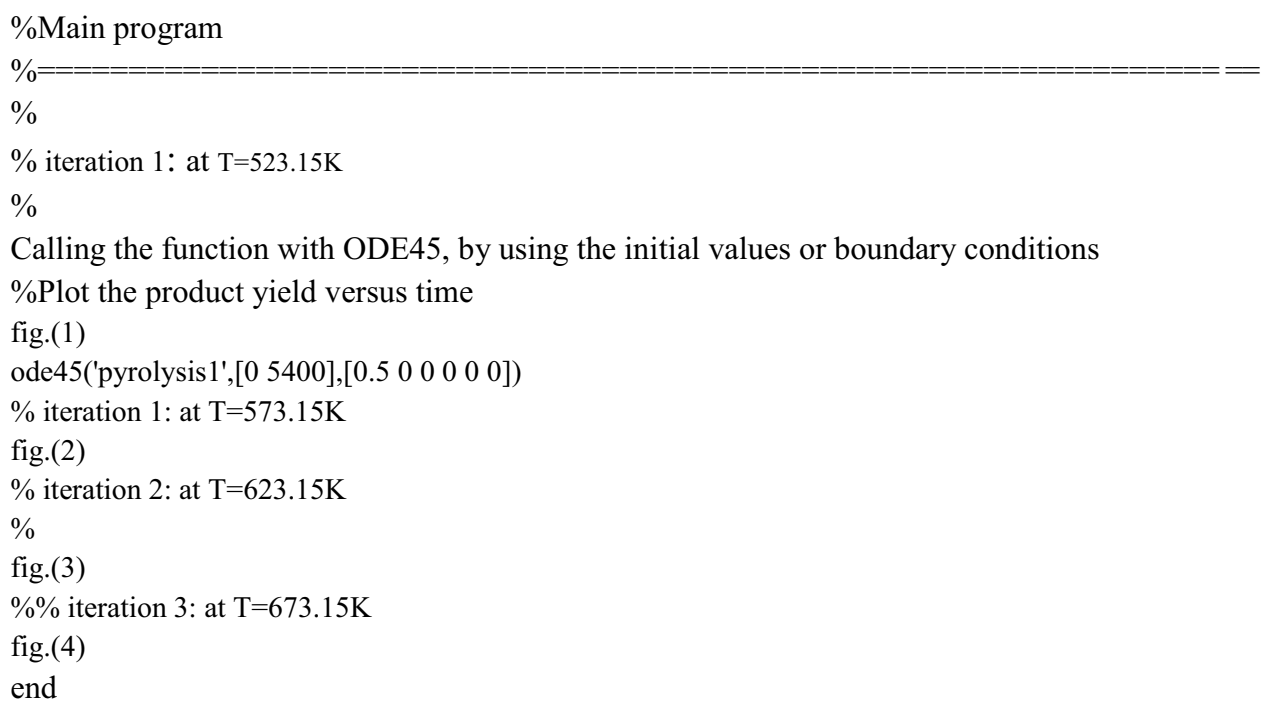

The flowcharts below describe the steps or algorithm 1 and 2, respectively in a graphical form, as well as the main program (see Fig. 2).

Fig. 2 Flowing chart describing the MATLAB 045 function

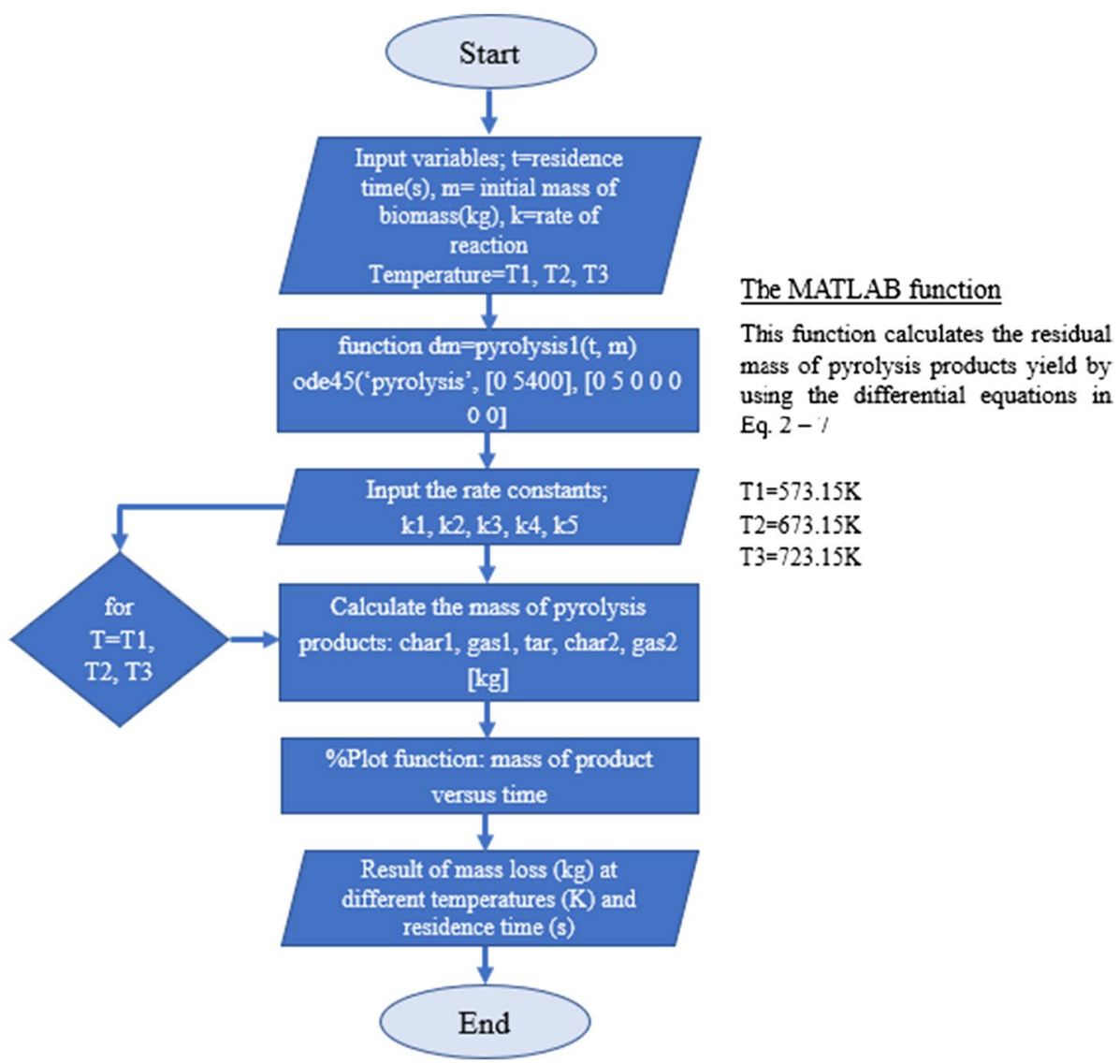




\section{Results and discussion}

The following rate constants at varying temperatures as computed in MATLAB is shown in Table 2. These rate of reaction constants were used to compute the residual mass of the wood biomass at time, $t=0-9000 \mathrm{~s}$ (see predicted residual mass of pyrolysis products in Fig. 2). It was observed that the rate of reaction increased with temperature. The rate constants in the present study as shown in Table 2 are in agreement with that of a multi-step thermogravimetric analysis and kinetics modeling of isothermal carbonization of wood in an inert atmosphere in the works of [29], which ranged from 0.00000122 to $0.0104 \mathrm{~s}^{-1}$. The authors did not predict pyrolysis products, only kinetics and rate constants were reported.

The following graphs shows the mass of pyrolysis product yield at different temperatures and time intervals (see Fig. 3). The graphs were obtained from the MATLAB ODE solver implemented in the software to solve the set of differential equations in Eqs. (2-7). As seen in Fig. 1, the initial mass of the biomass is $0.5 \mathrm{~kg}$ which diminishes as pyrolysis takes place from initial time $t(0 \mathrm{~s})$ to the final time as well as the change in temperature. Additionally, as the mass of biomass decreases the pyrolysis products increases until tar is finally consumed at secondary reaction (see Table 3) which shows that the values of the product yield.

In Fig. 3, it was observed that, as the mass of biomass decrease with time, the pyrolysis products such as char, $\operatorname{tar}$ (bio-

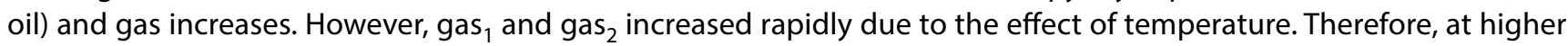
temperatures the mass of gas increased while char decreased. At $673.15 \mathrm{~K}$, tar (bio-oil) is consumed completely, mass of $\operatorname{tar} \cong 0$ (see Fig. $4 b, c, e, f$ ). This is in agreement with the two-step pyrolysis reaction scheme in Fig. 1. The negative sign in Table 3 indicates exothermic reaction which leads to an increase in the entropy of the surroundings. An exothermic reaction occurs when the temperature of the system increases due to the evolution of heat. This confirms the modified two-step pyrolysis reaction scheme in Fig. 1 which is in agreement with the works of Di Blasi [26] and Fantozzi et al. [27]. In Table 3 the \%biochar and gas yield produced during the simulation is in tandem with the findings of Ojolo et al. [30] as shown in Fig. 4.

In Table 4, we observed tar (bio-oil) is decomposed to form gas and gas $_{2}$ (i.e., the percentage of gas in superscript of $a^{\prime}$ and $b^{\prime}$ ) during primary and secondary reaction scheme (see two-step pyrolysis reaction scheme in Fig. 1). The findings of the present study agree strongly with that of Ojolo et al. [30] who reported that when temperature increases above $473 \mathrm{~K}$, biomass begins to decompose into char, tar (bio-oil) and gaseous products until it reaches a temperature $723 \mathrm{~K}$ after $225 \mathrm{~s}$ of residence time. That the production rate of char is higher than that of tar and gas. This validates the values given in two-step pyrolysis reaction scheme of this study.

\section{Validation of the algorithm}

The final, but censorious step in modeling is validation [31]. This step is accomplished by comparing the mass loss rate obtained from the pyrolysis experiments to those predicted by numerical simulation. This methodology has been successfully applied to a number of non-charring $[32,33]$ as well as charring $[34,35]$ processes. The model developed in the present study is compared with the isothermal biomass loss experiments conducted by Lina Samuelsson at Lulea University [36, 37] and the model developed by reaction model developed by Ojolo et al. [30]. Although, a comparison between the mass of pyrolysis products in the present study using numerical method and the concentration of products of during pyrolysis using analytical method by Ojolo et al. [30] showed very close resemblance in graphs plotted. The curves in the graphs showed huge similarity (see Fig. 4). However, the differences in the plots can be account for the residence time and number of pyrolysis products predicted.

The experimental procedure used by Samuelsson [36] for the pyrolysis of wood is discussed below. In the experiments, Norway spruce wood chips of three different thicknesses were prepared. The TGA setups did not include any

Table 2 Rate of reaction constants obtained from MATLAB computation

\begin{tabular}{llllll}
\hline Temperature $(\mathrm{K})$ & $\mathrm{k}_{1}$ & $\mathrm{k}_{2}$ & $\mathrm{k}_{3}$ & $\mathrm{k}_{4}$ & $\mathrm{k}_{5}$ \\
\hline 573.15 & 0.0001212 & 0.0002211 & 0.0001451 & 0.0006823 & 0.00001590 \\
673.15 & 0.0019000 & 0.0074000 & 0.0040000 & 0.0195000 & 0.00045497 \\
773.15 & 0.0149000 & 0.1004000 & 0.0471000 & 0.2336000 & 0.00550000 \\
\hline
\end{tabular}

$\mathrm{k}=$ rate of reaction constant from arenius equation (Eq. 1) 

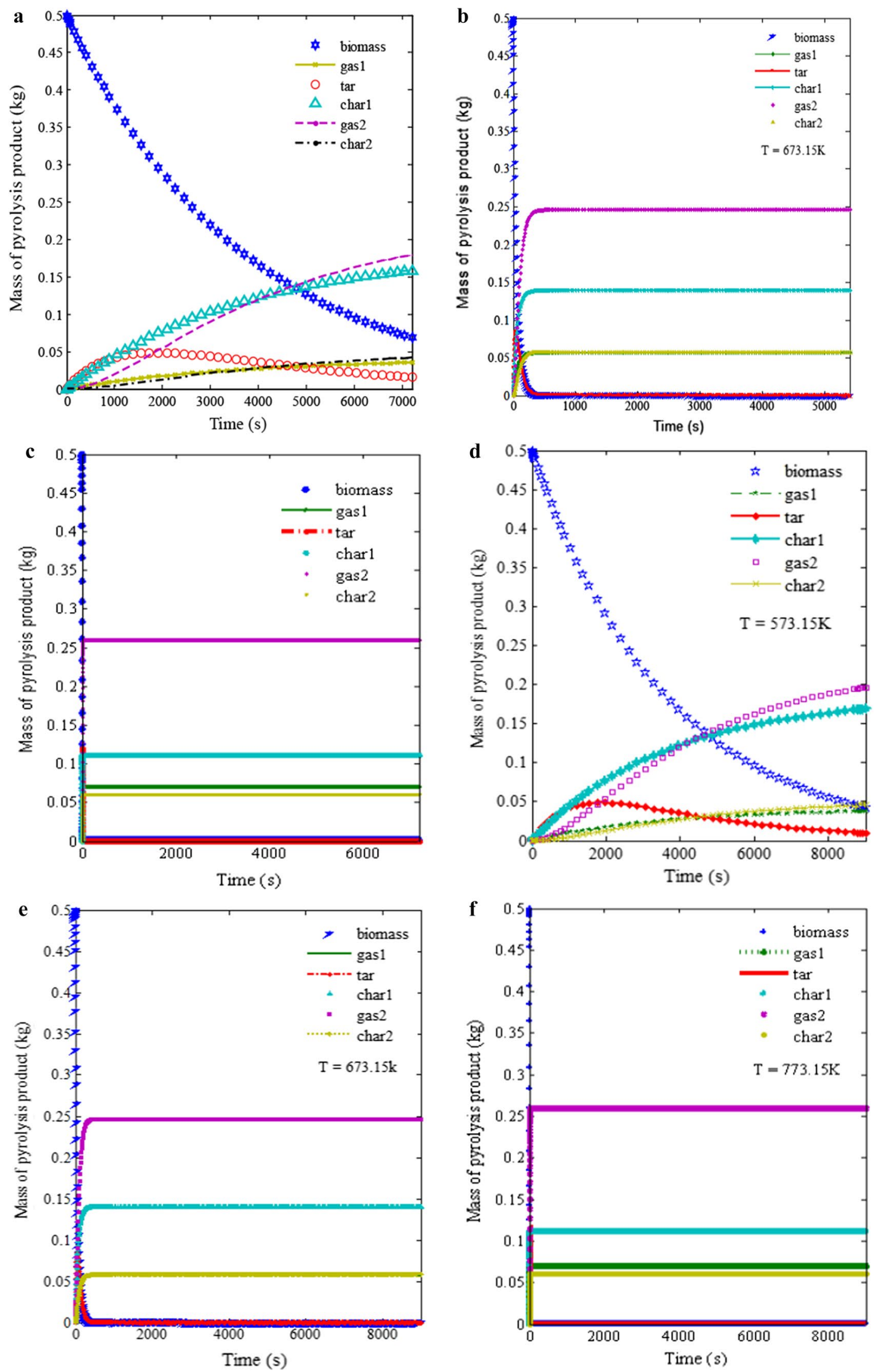

Fig. 3 Variation residual mass of pyrolysis products from MATLAB algorithm solution method. a $573.15 \mathrm{~K}$, b $673.15 \mathrm{~K}$, c $773.15 \mathrm{~K}$ at 7200 , 5400 and $5400 \mathrm{~s}$, d $573.15 \mathrm{~K}$, e $673.15 \mathrm{~K}$, f $773.15 \mathrm{~K}$ at $9000 \mathrm{~s}$ 
Table 3 Mass of char produced from primary and secondary reactions

\begin{tabular}{|c|c|c|c|c|c|}
\hline Time (s) & Temp (K) & $\begin{array}{l}\text { Mass of biochar } \\
(\mathrm{kg})\end{array}$ & Energy (KJ) & & \\
\hline 7200 & 573.15 & $0.1587^{a}$ & $0.0419^{b}$ & $66.65^{a}$ & $-1.676^{b}$ \\
\hline 5400 & 673.15 & 0.1392 & 0.0578 & 58.46 & -2.312 \\
\hline 7200 & 773.15 & 0.1114 & 0.0604 & 46.79 & -2.416 \\
\hline 9000 & 573.15 & 0.1686 & 0.0459 & 70.81 & -1.836 \\
\hline 9000 & 673.15 & 0.1392 & 0.0578 & 58.46 & -2.312 \\
\hline 9000 & 773.15 & 0.1114 & 0.0604 & 46.79 & -2.416 \\
\hline
\end{tabular}

Initial mass of biomass, $0.5 \mathrm{~kg}$

${ }^{a}$ Obtained from primary reaction (endothermic reaction)

${ }^{b}$ Obtained from secondary reaction (exothermic reaction)
Fig. 4 Comparison between (a) mass of pyrolysis products in present study using numerical method and (b) concentration of products of during pyrolysis using analytical method Ojolo et al. [30]
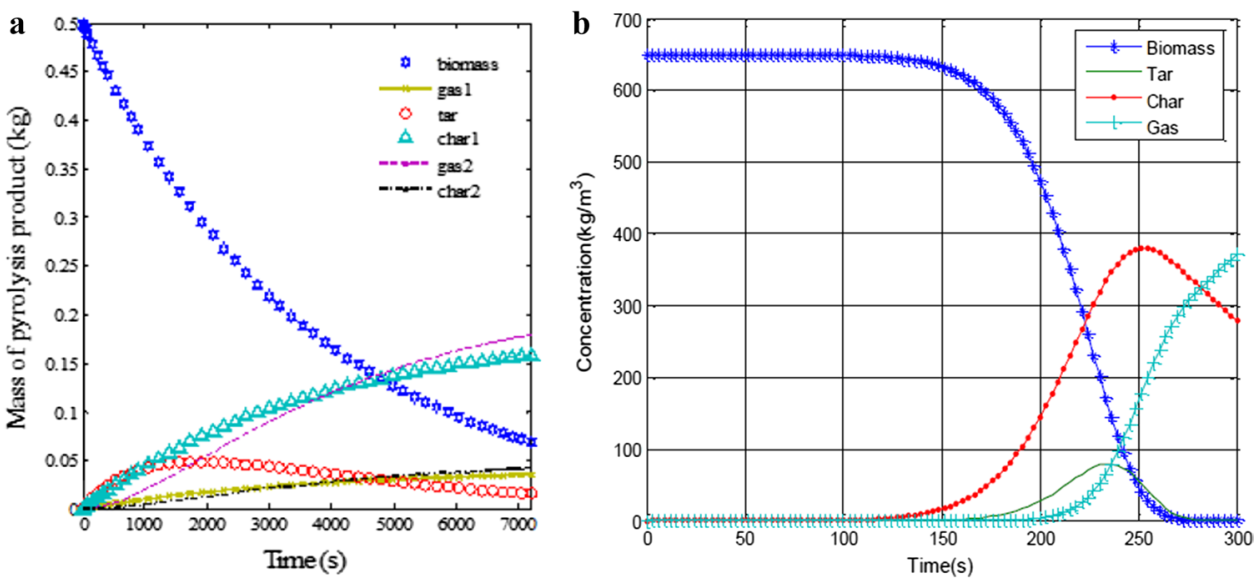

Table 4 Pyrolysis product yield in percentage

\begin{tabular}{llllcrl}
\hline Time $(\mathrm{s})$ & Temp $(\mathrm{K})$ & $\mathrm{m}_{\mathrm{B}}(\mathrm{kg})$ & Biochar $(\%)$ & Gas $(\%)$ & & \\
\hline 7200 & 573.15 & 0.5 & $31.70^{\mathrm{a}}$ & $8.38^{\mathrm{b}}$ & $7.08^{\mathrm{a}}$ & $35.86^{\mathrm{b}}$ \\
5400 & 673.15 & 0.5 & 27.84 & 11.56 & 11.55 & 49.20 \\
7200 & 773.15 & 0.5 & 22.28 & 12.08 & 13.95 & 51.68 \\
9000 & 573.15 & 0.5 & 33.72 & 9.180 & 7.53 & 39.24 \\
9000 & 673.15 & 0.5 & 27.84 & 11.56 & 11.55 & 49.20 \\
9000 & 773.15 & 0.5 & 22.28 & 12.08 & 13.95 & 51.68 \\
\hline
\end{tabular}

${ }^{\text {a Primary products }}$

${ }^{b}$ Secondary products, $\mathrm{m}_{\mathrm{B}}$, mass of biomass

instrumentation for gas analysis which limits us to predict solely the solid mass fraction as a function of temperature and time. The installed auto-sampler, together with the fast cooling of the furnace after finished runs make this instrument suitable for kinetic studies needing many repetitions at several heating rates. After each pyrolysis experiment the sample basket containing the wood chips was withdrawn from the furnace and placed in the purge zone to cool down before removing the char from the basket. The mass of the pre-dried sample chip and the resulting char was measured in an external balance (LPW-723, VWR). For all chip thicknesses the sample mass measured in the external balance varied less than $10 \mathrm{mg}$ from the value measured in the macro-TGA. The experiment was performed at each isothermal temperature, i.e., at 574, 597, 615, 637 and $676 \mathrm{~K}$. The minimum dwelling time for the medium and thick chips was 44 min and the longest time was $240 \mathrm{~min}$.

At all temperatures apart from $573.15 \mathrm{~K}$, the model mass loss rates are higher than the experiments. At $673.15 \mathrm{~K}$ this temperature, the numerical simulation using ode 45 function gives a char yield of $27.84 \%$ with the yield from the experiment by Samuelsson [36] been $22 \%$ (error $=-0.26$ ). The maximum error from experimental results of past works is 
observed at the lowest temperature, an error of 0.22 . From $573.15 \mathrm{~K}$ to $673.15 \mathrm{~K}$, the model yield ranges from $31.7-33.72 \%$ to $27.84 \%$ while experimental yield decreases from 44 to $22 \%$. It is pertinent to note that all the parameters required to test the model were either independently and directly computed or estimated from past works. This is compared with the experimental data of Samuelsson [36] using spruce wood chips. The experimental data from literature shows good agreement with the present prediction of \%char yield.

To evaluate the accuracy and performance of the algorithm, predicted values was compared with experimental data from literature using the percentage error as a function of error using Eq. (10) according to [38, 39]:

$$
\text { Error }=\frac{\text { Experimental value }- \text { Predicted value }}{\text { Experimental value }} .
$$

A comparison of the rate of production of pyrolysis products measured in the experiments obtained from past work (secondary data) to that predicted by the model solved using ODE45 function was used to validate the model's parameters. This comparison was made using only primary \%char yield $\left(\right.$ char $\left._{1}\right)$, since no work has been done on prediction of secondary char $_{2}$. This rate, also referred to as mass loss, multiplied by the effective heat of combustion of these products, yields the heat release rate, which is the single most important quantity characterizing material flammability [40]. Representative comparisons between the experimental work from literatures and simulated mass loss rates. All mass loss rates demonstrate a reasonable agreement with other studies.

\title{
5 Conclusion
}

MATLAB allows for a very simple implementation of the solution to differential equations involving two-step parallel pyrolysis of biomass and ODE45 functions as discussed in this study. Many researchers have not looked into the solution technique for a two-step parallel pyrolysis reaction to predict the by-products. In the present study, we use the results of the pyrolysis products predicted from the numerical simulation to compare with experiments from past works, a good agreement was achieved. Although, the kinetic equations used in this study are that of slow pyrolysis for wood biomass. The algorithm developed in this work is simplified, easy to use, and can be applied to any type of biomass undergoing parallel pyrolysis reaction if the kinetic parameters are known. Therefore, we have proposed this algorithm for the solution to pyrolysis models involving a two-step kinetic scheme which we have showed how it can be efficiently solved using MATLAB ODE45 function.

Acknowledgements Authors are thankful to IBIBATH Multi-Services and Department Agricultural and Bioresources Engineering, Michael Okpara University of Agriculture, Umudike, Abia State, Nigeria for providing the enabling environment for the research.

\begin{abstract}
Authors' contributions ITH carried out the literature review, research design, prepared the manuscript text and wrote the MATLAB script; MCN performed the simulation and manuscript edition; FIA prepared the algorithm and flowcharts and compiled the input data. OMO helped in the literature review and manuscript preparation; OEO performed the validation and interpretation; KO-A did the final review and corrections. All authors read and approved the final manuscript.
\end{abstract}

Declarations

Competing interests Authors declare no conflict of interest.

Open Access This article is licensed under a Creative Commons Attribution 4.0 International License, which permits use, sharing, adaptation, distribution and reproduction in any medium or format, as long as you give appropriate credit to the original author(s) and the source, provide a link to the Creative Commons licence, and indicate if changes were made. The images or other third party material in this article are included in the article's Creative Commons licence, unless indicated otherwise in a credit line to the material. If material is not included in the article's Creative Commons licence and your intended use is not permitted by statutory regulation or exceeds the permitted use, you will need to obtain permission directly from the copyright holder. To view a copy of this licence, visit http://creativecommons.org/licenses/by/4.0/.

\section{References}

1. Rajeswara RT, Sharma A. Pyrolysis rate of biomass materials. Energy. 1998;23(11):973-8.

2. Grieco E, Baldi G. Analysis and modelling of wood pyrolysis. Chem Eng Sci. 2011;66:650-60.

3. Cha JS, Park SH, Jung SC, Ryu C, Jeon JK, Shin MC, Park YK. Production and utilization of biochar: a review. J Ind Eng Chem. 2016;40:1-152. 
4. Sukale Y, Daftardar-Gejji V. New numerical methods for solving differential equations. Int J Appl Comput Mathe. 2017;3(3):1639-60.

5. Atkinson KE, Han W, Stewart D. numerical solution of ordinary differential equations. Numerical solution of ordinary differential equations. Wiley Blackwell; 2011.

6. Boyce WE, Di-Prima RC. Elementary differential equations and boundary value problems. Wiley; 2001.

7. Suli E, Mayers DF. An introduction to numerical analysis. Cambridge: Cambridge University Press; 2003.

8. Coombes KR, Hunt BR, Lipsman RL, Osborn JE, Stuck GJ. Differential equations with MATLAB. Wiley; 2000.

9. Edwards $\mathrm{CH}$, Penny DE. Differential equations and boundary value problems: computing and modeling. Prentice Hall; 2000.

10. Pyle D, Zaror C. Heat transfer and kinetics in the low temperature pyrolysis of solids. Chem Eng Sci. 1984;39(1):147-58.

11. Sobamowo G, Ojolo SJ, Osheku CA, Kehinde AJ. Kinetic modeling and simulation of pyrolysis of shrinking biomass particle in fixed bed gasifier. Iran J Energy Environ. 2016;7(1):18-30.

12. Yang YB, Phan AN, Ryu C, Sharifi V, Swithenbank J. Mathematical modelling of slow pyrolysis of segregated solid wastes in a packed-bed pyrolyser. Fuel. 2007;86(1):169-80.

13. Shafizadeh F, Chin PP. Thermal deterioration of wood. In: ACS Symposium Series American Chemical Society; 1977.

14. Thurner F, Mann U. Kinetic investigation of wood pyrolysis. Ind Eng Chem Process Des Dev. 1981;20(3):482-8.

15. Chan WCR, Kelbon M, Krieger BB. Modelling and experimental verification of physical and chemical processes during pyrolysis of a large biomass particle. Fuel. 1985;64(11):1505-13.

16. Font R, Marcilla A, Verdu E, Devesa J. Kinetics of the pyrolysis of almond shells and almond shells impregnated with cobalt dichloride in a fluidized bed reactor and in a pyroprobe 100. Ind Eng Chem Res. 1990;29(9):1846-55.

17. DiBlasi C, Russo G. Modeling of transport phenomena and kinetics of biomass pyrolysis. In: Advances in thermochemical biomass conversion. Netherlands: Springer; 1993. p. 906-21.

18. Janse A, Westerhout R, Prins W. Modelling of flash pyrolysis of a single wood particle. Chem Eng Process. 2000;39(3):239-52.

19. Babu B, Chaurasia A. Modeling, simulation and estimation of optimum parameters in pyrolysis of biomass. Energy Convers Manage. 2003;44(13):2135-58.

20. Koufopanos C, Lucchesi A, Maschio G. Kinetic modelling of the pyrolysis of biomass and biomass components. Can J Chem Eng. 1989;67(1):75-84.

21. Babu B, Chaurasia A. Heat transfer and kinetics in the pyrolysis of shrinking biomass particle. Chem Eng Sci. 2004;59(10):1999-2012.

22. Butcher JC. Numerical methods for ordinary differential equations. John Wiley. The Atrium, Southern Gate, Chichester, West Sussex PO19 8SQ, England, 2nd Edition; 2008.

23. Houcque D, Mccormick, RR. Applications of MATLAB: ordinary differential equations (ODE). 2008;101-323.

24. Nakamura S. Numerical analysis with MATLAB. Prentice Hall; 2002.

25. The MathWorks Inc. MATLAB: SP2 R14. The MathWorks Inc; 2019.

26. Di Blasi C. Heat momentum and mass transport through a shrinking biomass particle exposed to thermal radiation. Chem Eng Sci. 1996;51:1121-32.

27. Fantozzi F, Desideri U, Bartocci P, Colantoni S. Rotary Kiln slow pyrolysis for syngas and char production from biomass and waste-Part II: working envelope of the reactor. ASME J Eng Gas Turbines Power. 2007;129:901-7.

28. Nurhidayah MN, Adilah S, Nurhayati A. Slow pyrolysis of cassava wastes for biochar production and characterization. Iran J Energy Environ. 3: Special Issue on Environmental Technology. 2012;60-65.

29. Grioui N, Halouani K, Zoulalian A, Halouani F. Thermogravimetric analysis and kinetics modeling of isothermal carbonization of olive wood in inert atmosphere. Thermochim Acta. 2006;440(1):23-30.

30. Ojolo SJ, Osheku CA, Sobamowo MG. Analytical investigations of kinetic and heat transfer in slow pyrolysis of a biomass particle. Int J Renew Energy Dev. 2013;2(2):105-15.

31. Stoliarov SI, Li J. Parameterization and validation of pyrolysis models for polymeric materials. Fire Technol. 2016;52(1):79-91.

32. Li J, Stoliarov SI. Measurement of kinetics and thermodynamics of the thermal degradation for non-charring polymers. Combust Flame. 2013;160:1287-97.

33. Li J, Gong J, Stoliarov SI. Gasification experiments for pyrolysis model parameterization and validation. Int J Heat Mass Transf. 2014;77:738-44.

34. Li J, Stoliarov SI. Measurement of kinetics and thermodynamics of the thermal degradation for charring polymers. Polym Degrad Stab. 2014;106:2-15.

35. Li J, Gong J, Stoliarov SI. Development of pyrolysis models for charring polymers. Polym Degrad Stab. 2015;115:138-52.

36. Samuelsson LN. Isoconversional analysis for the prediction of mass-loss rates during pyrolysis of biomass. 2016.

37. Marc, M. Numerical modelling of wood pyrolysis. Master of Science Thesis in Chemical Engineering, Department of Chemical Engineering, Royal Institute of Technology. Stockholm, Sweden; 2016.

38. Mohajeri L, Abdul AH, Isa MH, Zahed MA. A statistical experiment design approach for optimizing biodegradation of weathered crude oil in coastal sediments. Bioresour Technol. 2010;101:893-900.

39. Agarry SE, Ogunleye OO. Box-behnken designs application to study enhanced bioremediation of soil artificially contaminated with spent engine oil using bio-stimulation strategy. Int J Energy Environ Eng. 2012;3:31-4.

40. Quintiere JG. Fundamentals of fire phenomena. Chichester, UK: Wiley; 2006.

41. Jalan RK, Srivastava VK. Studies on pyrolysis of a single biomass cylindrical pellet kinetic and heat transfer effects. Energy Convers Manage. 1999;40:467-94.

42. Di Blasi C. Modeling chemical and physical processes of wood and biomass pyrolysis. Prog Energy Combust Sci. 2008;34(1):47-90.

43. Di Blasi C. Analysis of convection and secondary reaction effects within porous solid fuels undergoing pyrolysis. Combust Sci Technol. 1993;90:315-40.

44. Liden AG, Berruti F, Scott DS. A kinetic model for the production of liquids from the flash pyrolysis of biomass. Chem Eng Commun. 1988;65:207-21.

Publisher's Note Springer Nature remains neutral with regard to jurisdictional claims in published maps and institutional affiliations. 